\title{
NOMINALISMO METODOLÓGICO EN MICHEL FOUCAULT: MICRO Y MACRO
}

\author{
DARÍO PERALTA \\ Universidad Nacional de General Sarmiento
}

\begin{abstract}
RESUMEN: Más allá de las tres temáticas (saber, poder y sujeto), la gubernamentalidad introduce nuevos interrogantes que complejizan la filosofía de Michel Foucault. Se investigará los avatares de esta etapa previa a la cuestión de la subjetividad. Allí se anuncia el problema de la población y el bio-poder, pero se diluye frente al tema de la relación del gobierno con el Estado, y en especial del neoliberalismo en Alemania y EE.UU. en la década de los 50. Estas transformaciones se deben a dos componentes metodológicos: el nominalismo y la discontinuidad histórica. Se estudiará las relaciones entre tres dispositivos de poder (mecanismo jurídico de soberanía, disciplinario y de seguridad gubernamental) y sus mutaciones históricas. Se cuestiona que los tres dispositivos se conectarían en un sistema triangular, con suficiente complementariedad. Por el contrario, se enfatizará sus tensiones, aunque esto no aminora el desarrollo en dos planos en virtud de los campos denominados macro y microfísica del poder.
\end{abstract}

PALABRAS CLAVES: nominalismo, modelo de guerra, gobierno, neoliberalismo, macro y microfísica del poder.

\section{Methodological nominalism Michel Foucault: micro and macro}

ABSTRAC: Beyond the three themes (knowledge, power and subject), governmentality introduces new questions that complicate the philosophy of Michel Foucault. The ups and downs of this stage prior to the issue of subjectivity will be investigated. There the problem of population and bio-power advertised, but is diluted address the topic of the government's relationship with the state, and especially of neoliberalism in Germany and the US in 50s. These transformations due to two methodological components: nominalism and historical discontinuity. The relationships between three power devices (legal mechanism sovereignty, disciplinary and government security) and its historical changes will be studied. It argues that the three devices would be connected in a triangular system with sufficient complementarity. On the contrary, tensions will be emphasized, although this does not diminish the development in two planes, which are called macro- and microphysics of power.

KEY WORDS: nominalism, model war, government, neoliberalism, macro and microphysics of power.

\section{INTRODUCCIÓN}

Es parte de la tradición presentar el corpus de los textos de Michel Foucault como divididos en tres etapas: arqueología, genealogía y ética ${ }^{1}$. El propio Foucault, en un texto titulado "Autorretrato»² (y que firma con un seudónimo),

1 Díaz, E. La filosofía de Michel Foucault, Biblos, Buenos Aires, 2003, p. 13.

Morey, M «Introducción: la cuestión del método» en Foucault, M., Tecnologías del yo y otros textos afines, Paidos, Buenos Aires, 2008. pp. 9-13. El autor afirma: «Convencionalmente, suelen distinguirse, en la obra de Foucault, tres etapas intelectuales» p. 10.

2 Foucault, M. "Autorretrato». Revista La Letra «A», 2 (3), Buenos Aires, (1991). Fue publicado en Dictionaire des philosophes (París: PUB, 1984), Vol. I, págs. 941-944, con el seudónimo Maurice Florence. 
ratifica esta interpretación. La cual parece proceder de la introducción al segundo volumen de la Historia de la sexualidad, El uso de los placeres. En éste, Foucault señala que su estudio sobre la sexualidad atraviesa tres ejes: la formación de los saberes, los sistemas de poder y las formas para reconocerse como sujetos $^{3}$.

Sin embargo, con la emergencia de la cuestión de la gubernamentalidad, aparecen nuevas problemáticas, nuevas hipótesis de lecturas que renuevan el interés por el pensamiento foucaultiano. Algunos especialistas interpretan que este bloque signado por el problema del gobierno actúa como una bisagra entre el período de su teoría del poder y su última fase centrada en la ética como práctica de libertad. Francisco Vázquez García afirma que la noción de 'biopolítica' funcionó en cierto modo como un puente entre los análisis del poder, anteriores a 1976 y los que, bajo la égida del concepto de "gobierno», se pusieron en marcha desde $1978^{\prime \prime}$.

Se considera que los estudios realizados por Foucault en sus cursos son de carácter explorativo y algunos de ellos sufrieron modificaciones en el transcurso de su presentación frente a los objetivos que inicialmente el propio filósofo había planteado. Foucault, en Seguridad, territorio y población ${ }^{5}$ se propone realizar un estudio de los mecanismos de seguridad, pero luego realiza una historia de la gubernamentalidad. Si bien el problema del gobierno moderno tiene que ver con las libertades de la población, el estudio de los dispositivos de seguridad parece diluirse frente al tema de la relación del gobierno con el Estado. Otro tanto ocurre en El nacimiento de la biopolítica ${ }^{6}$, donde nos promete investigar sobre el biopoder y termina por realizar un estudio del neoliberalismo de mitad del siglo XX, en Alemania y EE.UU.

El presente texto sostiene la idea, según la cual, Michel Foucault no logró realizar una sistematización de sus investigaciones sobre una teoría del poder. Aquí se interroga cuán foucaultiano sería postular un análisis sistemático de los fenómenos de la actualidad socio-política. Sostenemos que hay dos rasgos metodológicos que caracterizan cualquier investigación foucualtiana: el nominalismo - con un fuerte sesgo empirista - y la discontinuidad histórica. Se intentará mostrar la complejidad que conlleva poner en relación los tres dispositivos de poder estudiados por Foucault (mecanismo jurídico de soberanía,

3 Foucault, M. Historia de la sexualidad 2: El uso de los placeres, Siglo XXI, Madrid 2002, p. 8 .

4 Vázouez García, F. «De la microfísica del poder a la gubernamentalidad neoliberal. Nota sobre la actualidad filosófico-política de Michel Foucault.» En Revista Contrahistoria (6), 12, 2009, pp. 71-92. La afirmación del autor parece estar sustentada en DEAN, M.: Governmentality. Power and Rule in Modern Society, ver nota al pie $\mathrm{N}^{\circ} 6$ p. 4

http://rodin.uca.es/xmlui/bitstream/handle/10498/9165/ArtContrahis.pdf? sequence $=1 \&$ isAllowed $=\mathrm{y}$

5 Foucault, M. Seguridad, territorio, población. Curso en el Collage de France (1977-1978), Fondo de Cultura Económica, Buenos Aires, 2006, p. 18.

6 Foucault, M. Nacimiento de la biopolitica. Curso en el College de France (1978-1979), Fondo de Cultura Económica, Buenos Aires, 2007, p. 40. 
disciplinario y de seguridad gubernamental). Se analizarán las tensiones entre los dispositivos y sus mutaciones históricas en virtud de dos campos de estudios lo macro y la microfísica del poder.

\section{La PROBLemÁtica SOBRE lo SISTEMÁtico en FouCAULT}

El autor Francisco Vázquez García se propone mostrar el cambio que se da en el pensamiento de Michel Foucault, cuando éste indaga la relación entre gubernamentalidad y biopolítica en los años 77 y 78 . El objetivo de Vázquez García es ver cómo desde el modelo de gubernamentalidad es posible analizar el gobierno neoliberal ${ }^{7}$. Para este autor, Foucault se ve en la necesidad de abandonar el modelo de guerra — propuesto en Defender la sociedad de $1976^{8}$ - y proponer un nuevo modelo analítico de poder. El modelo de guerra entiende al poder como un conjunto de relaciones y enfrentamientos móviles. Así queda cuestionada la centralidad del Estado, fijado por los modelos tradicionales —Contractualista y Marxista_- En el modelo de guerra, el poder se despliega a un nivel que Foucault denomina «microfísica». El poder emana de este nivel, luego, el Estado capta una porción de esta organización de las cosas y estructura su forma jurídica del poder. Vázquez García afirma de esta manera se hace visible: «la cristalización de las grandes estrategias estatales al apoyarse en la fuerza ejercida en esta escala molecula» ${ }^{9}$.

En 1976, en la última clase de Defender la sociedad, y también en Voluntad de Saber ${ }^{10}$, M. Foucault señala un nuevo de tipo de poder al que denomina «Biopolítica». Los dos modelos estudiados previamente, a saber, el poder soberano y el poder disciplinario, no parecen ajustarse a este nuevo fenómeno. Es en Seguridad, territorio y población donde anuncia profundizar sus estudios sobre el bio-poder. Los dispositivos aplicados para este ejercicio son denominados «mecanismos de seguridad». Vázquez García cuestiona la preeminencia de la «microfísica del poder», así indica: "salvo algunas alusiones a la cristalización del Estado napoleónico a partir del complejo disciplinario insertado a escala molecular, el argumento de Vigilar y castigar apenas desarrolla esta conexión entre lo micro y lo macro» ${ }^{11}$.

Vázquez García sostiene la idea de un sistema triangular del poder. Lo expresa con más claridad en una nota al pie: «Frente a lecturas como las de Deleuze o Toni Negri, hay que insistir en que para Foucault la relación entre soberanía,

7 Vázouez García, F., o.c., p. 8.

8 Foucault, M. Defender la sociedad. Curso en el Collage de France (1975-1976), Fondo de Cultura Económica, Buenos Aires, 2000, p. 28.

9 Vázouez García, F., o. $c$., p. 2.

10 Foucault, M. Historia de la sexualidad 1: Voluntad de saber, Siglo XXI, Buenos Aires, 2008.

11 Vázouez García, F., o. c. p. 10. Entre los siglos XVI y XVIII se desplegó un poder soberado, que Vázquez García denomina gobierno «disposicional», p. 16 
disciplinas y mecanismos de seguridad no es de sucesión sino de articulación recíproca. Se trata de un «triángulo»"

Por nuestra parte, si bien es el propio Foucault en Seguridad, territorio y población quien indica que la relación puede ser entendida como un triángu$\mathrm{lo}^{13}$, nos interrogamos si esta nueva interpretación de la articulación de los tres tipos de poder viene a tirar por tierra el análisis tomado en dos niveles: macro y micro-poder. Nuestro postulado es el siguiente: es innegable la persistencia de mecanismos del poder soberano, sin embargo, en todos los análisis realizados por Foucault sólo se observan las mutaciones que han tenidos los mecanismos de legalidad soberana en relación - primero- con los dispositivos disciplinarios y luego con los dispositivos de seguridad poblacional. No consideramos acertada la perspectiva que enfatiza una triangulación de los dispositivos del poder político, sino que creemos necesario insistir en ver cómo se renuevan las relaciones entre lo micro y lo macro. Y que así aseguraríamos las posturas metodológicas nominalistas.

\section{DifERENCIAS ENTRE LOS MECANISMOS DE PODER}

Foucault en Seguridad, territorio y población señala que si bien se podrían trazar cortes históricos: el sistema legal soberano va desde la Edad Media hasta el siglo XVII-XVIII; el sistema disciplinario a partir del siglo XVIII; el sistema de seguridad sería imaginado como un elemento contemporáneo ${ }^{14}$. No obstante, esta lectura no atiende a lo complejo de las relaciones entre los sistemas ${ }^{15}$. Los mecanismos no se excluyen mutuamente, Foucualt lo explicita: «No hay era de lo legal, era de lo disciplinario y era de la seguridad $»^{16}$. Sólo podemos pensar una serie de edificios complejos que van a complicarse en un sistema de correlaciones.

(i) Foucault plantea una serie de ejemplos para diferenciar los mecanismos de poder:

1) LA LEPRA: la exclusión de los leprosos ya fue estudiada al inicio de Historia de la locura. Allí se demuestra que la reclusión de los enfermos mentales se realizó bajo el modelo de la segregación social de los leprosos en la Edad

12 Vázouez García, F., o. c., nota al pie $\mathrm{N}^{\circ}$ 36., p. 17

13 Foucault, M., Seguridad, territorio y población, p. 131.

14 Ibid., p. 21.

15 Ibid., Aquí presenta el ejemplo del robo:1) para la soberanía se aplica un castigo ejemplar; 2) para la disciplina hay una vigilancia y encarcelamiento; 3) para la seguridad hay un control estadístico. Empero, en (1) ya hay objetivos disciplinarios, porque el ejemplo se aplica sobre el resto de la población. Y si el robo fue perpetrado por un sirviente, el castigo sería de una severidad extrema. Ya que se reserva ese nivel de crueldad en casos importante por su probabilidad, lo que implica mecanismo de seguridad. Hay tensiones similares aparecen (2) y en (3).

16 Ibid., p. 23. 
Media. Muchos leprosarios son usados como hospitales en la época del Gran Encierro. Por medio de la reclusión en estos antiguos leprosarios se instalan allí todos los elementos asociales: vagabundos, libertinos, mendigos, impedidos e insensatos. Recién en el siglo XIX, se aplicará la distinción científica del enfermo mental de las otras figuras ${ }^{17}$.

2) LA PESTE: en Vigilar y castigar se señala que «si bien la lepra ha suscitado rituales de exclusión que dieron hasta cierto punto el modelo del gran Encierro, la peste suscitó los esquemas disciplinarios ${ }^{18}$. En el caso de la aparición de la peste, la ciudad es ocupada militarmente, es cercada y se ponen en cuarentena a los habitantes en sus propias casas. Se divide toda la zona en secciones: con síndicos, centinelas, y médicos. Es un espacio cerrado, recortado y vigilado con el objeto de evitar los contagios.

3) LA VIRUELA: en Seguridad, territorio y población, se plantea este problema en términos estadísticos ¿Cuántos son afectados? ¿Qué franja etaria es más aquejada? ¿Qué nivel de mortalidad ha alcanzado? ¿Qué peligros de contagios hay? ¿Qué posibilidades de inoculación hay? Así, desde el control sobre la población, se efectúa una modificación en la situación biológica de la especie. Hay un cálculo de costos de acuerdo a reglas sobre lo que es óptimo y aceptable para la población.

(ii) En función de este último ejemplo es posible emprender una analítica de los mecanismos de seguridad. Se estudiarán tres de sus componentes que permitirán diferenciarlos con los restantes dispositivos de poder. Las categorías analíticas son: el espacio, el acontecimiento y la normalización.

A) EL ESPACIO: en cuanto a lo legal-soberano, su poder se ejercía sobre un territorio, y sólo se toman a sus habitantes como una multiplicidad de súbditos sujetos a la voluntad del monarca. En cuanto a la disciplina, se ejerce sobre los cuerpos individuados. El cuerpo dócil es el efecto de una multiplicidad de tácticas disciplinaria (lo escolar, lo militar, lo penal, etc.) en un espacio cerrado. La disciplina es una modalidad de individuación de las multiplicidades. En cambio, para la seguridad, la ciudad es pensada en función del problema de la circulación (de provisiones, mercancías, aire, personas) para garantizar la higiene, el comercio exterior, conectar los caminos internos con las rutas exteriores y la vigilancia sobre la totalidad de la población. La seguridad será un objetivo a cargo del gobierno. La gubernamentalidad busca maximizar los datos positivos de la realidad poblacional, a su vez, minimizar los datos negativos y se abre a un futuro no controlable.

B) EL ACONTECIMIENTO: para la seguridad gubernamental, el acontecimiento que se debe evitar es la escasez. Es un momento en que la producción

17 Foucault, M., Historia de la locura en la época clásica (Vol. 1), Fondo de cultura económica, México, 2004, p. 78.

18 Foucault, M., Vigilar y castigar: nacimiento de la prisión, Siglo XXI, Buenos Aires, 2006, p. 202. 
de alimentos se ha detenido y se deben pensar cómo no llegar a la hambruna antes que las provisiones se acaben. Los efectos de la escasez son: el alza de precios, el acaparamiento, el descontento y la revuelta social. El gobierno debe actuar para que esta secuencia no se inicie, o de ser así, no se complete.

Hasta el siglo XVII, frente a la escasez, la legalidad-soberana y lo disciplinario tienen por objetivo prevenirla. El Estado toma un rol activo para fijar una limitación de los precios, prohibición del acopio, limitación de la exportación, restricción para limitar los cultivos. Se sustituyen productos en la siembra (en Francia, la vid es reemplazada por el trigo). Se aplica un control de precios que impide el acaparamiento y una legislación impositiva para limitar la circulación especulativa. El resultado de este proceso es reducir el costo de vida de los trabajadores, y así, abaratar los salarios. Pero esto acarrea pérdidas para el sector agricultor. La caída del precio del grano hace que la ganancia para el campesino sea inferior a su inversión. Esta pérdida hace que se reduzca la siembra para el año siguiente. Y esto genera escasez (lo que en realidad se pretendía evitar). Estas políticas fueron puestas en marcha por los mercantilistas durante el siglo XVII. Pero prontamente aparecieron críticas y un modelo alternativo: la fisiocracia. La libre circulación de granos garantiza la abundancia, y si esta nueva situación llegara a ser perjudicial (ej. la baja del precio) se aceptan mecanismo de acopio y de libre exportación para sostener el precio en alza. Esta ganancia repercute en la expansión de la siembra que asegura la abundancia. Y si ahora el alza de precio fuese lo perjudicial, esto se detiene y es compensado por la libre importación.

El pasaje del mercantilismo a la fisiocracia es lo que explica el advenimiento de la gubernamentalidad liberal. Los mecanismos de seguridad están ligados a la emergencia de la serie de dominios de saber, en particular: la economía política.

C) LA NORMALIZACIÓN: a toda ley le es intrínseca una normatividad, pero esta última es algo diferente de las técnicas de normalización. En Voluntad de saber, Foucault señala que, a partir del siglo XIX, la ley en su aspecto prohibitivo es complementada por el biopoder que pone en juego la norma centrada en funciones reguladoras ${ }^{19}$. Además, para la disciplina estas técnicas serán muy diferentes que, para la seguridad, al punto que decidirá llamar, en Seguridad, territorio y población, a la normalización disciplinaria con el término de 'normación'. La disciplina aplica una cuadrícula del espacio para lograr una percepción detallada de sus componentes, identificarlos y modificarlos. Además, hay una tipificación de los buenos gestos, necesarios para producir un cuerpo dócil y obediente. Hay una articulación adecuada y una secuenciación del cuerpo con los objetos y una coordinación de las tareas. Hay un adiestramiento progresivo y un control permanente. Por último, hay un poder de diferenciación

19 Foucault, M., Voluntad de saber, «No quiero decir que la ley se borre ni que las instituciones de justicia tiendan a desaparecer; sino que la ley funciona siempre más como una norma, y que la institución judicial se integra cada vez más en un continuum de aparatos (médicos, administrativos, etc.) cuyas funciones son sobre todo reguladoras.», p. 175 
entre los que alcanza un estado de aptitud óptimo y los ineptos que serán calificados de anormales.

La normativa disciplinaria se impone desde un modelo ideal. Se trata de ajustar los comportamientos a ese ideal. Lo normal se define en base a una norma y dado que es un proceso deductivo, por el cual, se define la normalidad, este proceso se denomina normación ${ }^{20}$.

En cambio, para la seguridad, ya en los siglos XVII-XVIII, la viruela era una enfermedad endémica de un alto índice de mortalidad ( 1 de cada 7,782 hab.) y la enfermedad reaparecía por oleada cada cinco o seis años. Los procedimientos de intervención fueron la inoculación, la variolización y la vacunación. Estas técnicas obtuvieron resultados estadísticos de éxito y certeza. Se integraron a las prácticas médicas - aun sin una confirmación científica, que sólo se alcanzará en el siglo XIX con Pasteur-por su semejanza con los demás dispositivos de seguridad.

Aparecen una serie de nociones estadísticas: «enfermedad reinante» ${ }^{21}$, «estudios de casos». Los casos se dividirán según la edad, las zonas, la profesión. Se calcula el «riesgo», aparecen riesgos diferenciales, para luego analizar las escalas de aceleración con la posibilidad de calcular las curvas de normali$\mathrm{dad}^{22}$. Su forma de intervención es la organización gubernamental en la forma de campañas de vacunación, higiene y prevención.

En fin, resumimos las diferencias más pronunciadas entre los mecanismos disciplinarios y los de seguridad en el siguiente cuadro comparativo:

\begin{tabular}{|c|c|}
\hline Disciplina & Seguridad \\
\hline $\begin{array}{c}\text { Concentra elementos heterogéneos y los } \\
\text { uniformiza en instituciones de encierro }\end{array}$ & $\begin{array}{c}\text { Configura series abiertas y de ampliación } \\
\text { al mercado mundial. }\end{array}$ \\
\hline $\begin{array}{c}\text { Examina y normativiza todas las } \\
\text { conductas hasta los mínimos detalles. }\end{array}$ & $\begin{array}{c}\text { Su máxima es dejar hacer, no intervenir } \\
\text { hasta un nivel aceptable por la } \\
\text { naturaleza. }\end{array}$ \\
\hline $\begin{array}{c}\text { Es una codificación positiva, fija qué } \\
\text { parámetros de normalidad se deben } \\
\text { alcanzar }\end{array}$ & $\begin{array}{c}\text { Regula la realidad social dada en función } \\
\text { de estadísticas. }\end{array}$ \\
\hline Genera una realidad artificial & Regula una realidad natural \\
\hline Aplica una normación trascendental & Aplica una normatividad estadística \\
\hline
\end{tabular}

20 Foucault, M., Seguridad, territorio y población, «para destacar el carácter primario y fundamental de la norma», p. 76.

${ }^{21}$ Foucault, M., El nacimiento de la clínica: una arqueología de la mirada médica, Siglo XXI, Buenos Aires 2001. "Hautesierck proponía un plan que comprendía cuatro series paralelas y sin límites: estudio de las topografías, observaciones meteorológicas, análisis de las epidemias y de las enfermedades reinantes, descripción de los casos extraordinarios»p. 52. Y también p. 162.

22 Foucault, M., Seguridad, territorio y población, p. 83. 
(iii) Por último, en tercer lugar, Foucault inquiere acerca de la relación de las formaciones de saber y la población. Si bien, en Las palabras y las cosas ${ }^{23}$, había indagado cómo en los siglos XVII-XVIII se produce una ruptura epistémica respecto a los tratamientos y abordaje. Se pasa de un análisis de la riqueza a la economía política, se pasa de la Historia Natural a la biología, y de la Gramática General a la filología histórica. En los tres casos se toma como punto de ruptura, como discontinuidad histórica, con un objeto tomado como natural y la práctica de la clasificación de sus componentes, y se toma al hombre como centro de esta nueva forma de investigación que dieron lugar a las ciencias humanas.

Ahora, por otra parte, en Seguridad, territorio y población, se analizan estos campos de saber nuevamente desde una nueva perspectiva:

(a) ECONOMÍA POLÍTICA: con el mercantilismo todavía se procede por un análisis de la riqueza ${ }^{24}$, pero desde que se considera los interrogantes de quién produce las riquezas y quién la extrae, la cuestión gira hacia la población como elemento indispensable. A este respecto, el ejemplo más claro es el estudio estadístico realizado por Malthus en razón al crecimiento y la mortalidad poblacional.

(b) BIOLOGÍA: se abandonan las técnicas de clasificación de los seres vivos y a partir de los siglos XVIII-XIX aparecen análisis internos del organismo con indicaciones referidas a las funciones anatómicas y su relación con el medio ambiente. Lamarck, Cuvier y Darwin ponen — según sus presupuestos teóricos-en vinculación a la población de los seres vivos con el medio ambiente según sus mutaciones orgánicas.

(c) LINGÜÍSTICA: la gramática general que también empleaba la clasificación se deja de lado. Con la filología histórica, aparece la preocupación por las relaciones, las transformaciones y la circulación de los recursos lingüísticos entre las distintas poblaciones de Europa. Estos estudios llegarán a postular finalmente una estructura sintáctica general del lenguaje y una misma raíz indoeuropea.

Por nuestra parte, nos atrevemos a señalar que no hay en concreto ningún cambio de perspectiva, que la discontinuidad está establecida en el mismo período histórico y por las mismas razones. Es decir, la población ya es un problema que aparecía en Las palabras y las cosas, por ejemplo: en relación con el bosque y su usufructo, el crecimiento de los productos agrícolas y cómo eso afecta a los salarios de los obreros ${ }^{25}$. Y si la temática abordada en la Historia

23 Foucault, M., Las palabras y las cosas: una arqueología de las ciencias humanas, Siglo XXI, Buenos Aires, 2013.

${ }^{24}$ Ibid., Para el Mercantilismo «el metal precioso era, de suyo, la marca de riqueza» p. 189.

25 Ibid., p. 273. «toda población, en caso de no encontrar recursos nuevos, está destinada a extinguirse; y, a la inversa, a medida que los hombres se multiplican emprenden trabajos más numerosos, más lejanos, más difíciles, menos fecundos de inmediato». p. 271. 
de la locura es retomada con un nuevo ímpetu en Vigilar y castigar, algo similar ocurre aquí. La temática abordada en Las palabras y las cosas se puede poner en relación con el problema de la gubernamentalidad y la población, mientras que en cada caso se rechazan los postulados universales: tales como Estado (en su sentido más abstracto), espíritu de un pueblo, astucia de la razón, etc., y se persiste con el estudio de casos de orden nominal. Y por lo tanto, en todos los casos examinados, se demuestra que la población no es un dato preexistente, sino más bien, es el resultado de la puesta en relación entre estrategias de gobierno, de dominios de saber y de un conjunto material dado históricamente.

\section{BiOPOLÍTICA Y LA GUBERNAMENTALIDAD}

Foucault usa por primera vez el término «biopolítica» en una conferencia en Río de Janeiro en 1974 titulada «El nacimiento de la medicina social». Allí sostiene que el capitalismo a comienzos del siglo XIX no propone la privatización de la salud, sino que lo profundiza como un asunto público. Toma al cuerpo como fuerza productiva, y por ello hay un control social de los cuerpos. «Para la sociedad capitalista lo que más importa es lo biopolítico, lo somático, lo corporal. El cuerpo es una realidad biopolítica; la medicina es una estrategia biopolítica ${ }^{26}$.

En Defender la sociedad, el filósofo francés considera que, a partir del siglo XIX, aparece un poder que se hace cargo de la especie humana, se inicia un proceso que podría denominarse estatización de lo biológico. Mientras que, en los mecanismos de soberanía, la vida y la muerte eran un asunto que dependía de la voluntad del soberano. Era el derecho soberano para hacer morir y dejar vivir. Era el derecho de espada el que hacía patente este poder para matar y su no ejecución era la actuación del derecho de dejar vivir. En el siglo XIX aparece una novedad, el derecho de hacer vivir y dejar morir, todo lo cual estará ligado a un nuevo ordenamiento de poder político. Si las técnicas disciplinarias emergen en el siglo XVIII, en el siglo XIX aparece algo nuevo, que no excluye a la disciplina, sino que la integra, la modifica en parte y surge gracias a ella ${ }^{27}$.

La biopolítica se aplica a los hombres, ya no como cuerpos individuados, sino como una masa poblacional en los procesos de la vida en tanto especie humana. Estos procedimientos de la biopolítica son los que hemos vistos como mecanismos de seguridad. La política atiende al crecimiento demográfico de la población, a la aparición de enfermedades endémicas, e intervendrá en base a cálculos de costos por medio de campañas gubernamentales y la aplicación será en la ciudad por medio de seguros (de trabajo, médico, social etc.). Los acontecimientos sobre los que se aplica son de carácter aleatorio, pero tomados en

26 Foucault, M., «El nacimiento de la medicina social» en Obras esenciales, Segunda Parte: Estrategias de poder, pp. 653-672, Paidós, Madrid, 2010, p. 657.

27 Ibid., p. 219 
términos estadísticos llegan a ser controlables. La seguridad no ejerce un poder sobre la muerte, sino sobre los índices de mortalidad. Es un poder que interfiere en los problemas de natalidad, longevidad y mortalidad. Un ejemplo es la inspección sobre la sexualidad, donde se mezclan mecanismos disciplinarios tales como el control sobre la masturbación - tema que ya había estudiado en Los anormales ${ }^{28}$ - con otros mecanismos de biopolítica como el control sobre la natalidad. Foucault sostiene que: «La sexualidad está exactamente en la encrucijada del cuerpo y la población. Compete, por tanto, a la disciplina, pero también a la regularización ${ }^{29}$.

En Voluntad de saber, retoma la cuestión del derecho de hacer vivir y dejar morir. Este poder sobre la vida se aplica de dos modos diferentes, que no se oponen. Uno, es un control del cuerpo, para educarlo, aumentar sus fuerzas y producir docilidad. En el otro, se controla al cuerpo, pero como soporte de los procesos biológicos por medios de «una serie de intervenciones y controles reguladores: una biopolítica de la población ${ }^{30}$. La dominación sobre la vida se da en la complementariedad de estas dos tecnologías de poder.

Asimismo, el biopoder está ligado a la consolidación del capitalismo. El Estado, desde sus instituciones, asegura las condiciones para el mantenimiento de las relaciones de producción dominante, pero también es necesario la existencia de un proceso de disciplinamiento de los agentes intervinientes y una regulación de la población en una serie de fenómenos biológicos como la salud o la reproducción sexual. «La articulación entre el crecimiento de los grupos humanos y la expansión de las fuerzas productivas y la repartición diferencial de la ganancia, en parte fueron posibles gracias al ejercicio del bio-poder en sus formas y procedimientos múltiples» ${ }^{31}$.

En Defender la sociedad, el filósofo francés se encarga de mostrar que el pasaje del modelo de guerra hacia un modelo de gobierno basado en la biopolítca no deja de tener enormes problemáticas. El derecho de matar que era un rasgo distintivo del poder soberano, reaparece en el siglo XIX en la biopolítica ligado a cuestiones raciales. Todos los enfrentamientos desde el inicio de la modernidad, luchas al interior de la sociedad, o luchas entre las naciones son asumidas bajo el modelo de una guerra de razas. Con el biopoder, el racismo pasa a ser una cuestión de Estado. Se configura una manera de fragmentar el campo biológico, de generar un desequilibrio entre los grupos que integran la población ${ }^{32}$. Se inserta una lógica binaria donde la posibilidad de vivir está ligada al deber

28 Foucault, M., Los anormales, Curso en el College de France (1974-1975), Fondo de Cultura Económica, Buenos Aires, 2007. Clase de 22 de enero de 1975 «el masturbador, el niño masturbador, es una figura novísima en el siglo XIX (o en todo caso a fines del siglo XVIII) y su campo de aparición es la familia» p. 64. El tema atraviesa toda la cursada, reaparece, por ejemplo, el 5 de marzo, respecto del discurso cristiano y la psicopatología sexual; o en la última clase, el 19 de marzo de 1975.

29 Foucault, M., Defender la Sociedad, p. 228

30 Foucault, M., Voluntad de Saber, p. 169

31 Ibid., p. 171.

32 Foucault, M., Defender la sociedad, pp. 230-231. 
de aniquilar al enemigo. Ya no se contenta con aniquilar al enemigo político, sino a toda una etnia racial, y con ello se refuerza la propia raza en su pureza. Todas estas premisas permiten con facilidad deducir el advenimiento de los Estados fascistas. El nazismo es un tipo de gobierno estatal que llevó al máximo los mecanismos disciplinarios y de seguridad racial ${ }^{33}$.

Deseamos enfatizar el aspecto crítico que tienen estos textos foucualtianos, ya que las explicaciones realizadas sobre los mecanismos regulatorios, sobre la gubernamentalidad, sobre la economía política ligada a la fisiocracia, al liberalismo clásico y al neoliberalismo aparecen en Seguridad, territorio y población y en Nacimiento de la biopolítica, a primera vista, como simples descripciones históricas, pero deben ser entendidas como lecturas con un fuerte espíritu crítico. Por este motivo, las prácticas de libertad que Foucault buscará a partir de El Uso de los placeres y Hermenéutica del sujeto (1982) ya no estarán conectadas en sentido estricto al modelo de gobierno.

Si bien Foucault había afirmado que la biopolítica se implementa de un modo similar a cualquier forma de Estado, aun así, existen enormes diferencias entre un Estado burocrático, un Estado fascista, un Estado totalitario y un Estado democrático liberal. En su intento de enfatizar el principio nominalista, el filósofo francés aclara que la emergencia de políticas neoliberales no puede ser calificada como fascistas porque con ello se pierden las características diferenciales de las formas gubernamentales.

El Estado, para Foucault, es una categoría universal que sólo puede ser comprendida por medio de las formas históricas concretas de cómo se entrelazan los mecanismos de poder. La gubernamentalidad es un sistema que se establece desde que aparece la población como un problema de gobierno. El filósofo francés desarrolla tres definiciones de gubernamentalidad. Es un conjunto de instituciones y procedimientos aplicados para regular los comportamientos generales de la población. Es una tendencia histórica que consolidó al gobierno como forma de poder y desarrolló una serie de saberes. Es un proceso histórico que explica cómo se pasa de un Estado jurídico medieval, y del Estado administrativo de los Absolutismos a un Estado gubernamental. La crítica foucaultiana se aplica a los estudios centrados en la noción de Estado entendida como un concepto que reflejaría una unidad y una funcionalidad rigurosa. Nada más lejano de los hechos. Por el contrario, la noción de gubernamentalidad revela las transformaciones y los juegos incesantes de poder referidos a los procedimientos, técnicas, e instituciones ligadas al poder político. Toda una travesía con enormes mutaciones que la simple noción de «Estado» no permite observar. Foucault señala que lo que caracteriza nuestra modernidad

33 «Los dos mecanismos, el clásico y arcaico que daba al Estado derecho de vida y muerte sobre sus ciudadanos, y el nuevo mecanismo organizado alrededor de la disciplina y la regulación, en síntesis, el nuevo mecanismo de biopoder, coincidieron exactamente. De modo que podemos decir lo siguiente: el Estado nazi hizo absolutamente coextensos el campo de una vida que ordenaba, protegía, garantizaba, cultivaba biológicamente y, al mismo tiempo, el derecho soberano de matar a cualquiera, no sólo a los otros, sino a los suyos», Ibid., p. 235. 
no es la estatización de la sociedad sino más bien la «gubernamentalización del Estado» ${ }^{34}$.

En Nacimiento de la biopolítica, Foucault retoma su investigación del año anterior, donde muestra que la Razón de Estado y el Estado de policía que habían guiado las formas de gobierno del Estado monárquico son reemplazadas por una racionalidad liberal de gobierno. Una nueva forma de racionalidad gubernamental ligada a los problemas de la industrialización y el crecimiento demográfico. La lógica de poder entre las naciones cambia al alcanzar un equilibrio europeo. No obstante, la razón liberal no deja de estar ligado a la expansión imperialista fuera del continente europeo. Una racionalidad guiada por la economía política y conectada a la organización de una biopolítica aplicada a la población ${ }^{35}$.

El liberalismo no debe ser entendido como un dispositivo que fomenta las tecnologías del yo, sino como una técnica de poder que toma al mercado como un mecanismo o régimen de veridicción y como una forma de limitación del ejercicio del poder público. Foucault se interroga ¿qué parámetro podemos usar para afirmar que el régimen monárquico centralizado posibilitaba más o menos libertad que el régimen liberal? Nuevamente, en función del nominalismo metodológico, el autor señala que la libertad no es universal, es una «relación actual entre gobernantes y gobernados» ${ }^{36}$. El liberalismo antes que garantizar tal libertad, es "consumidora de libertad». La gubernamentalidad liberal tiene la necesidad de las libertades económicas capitalistas. Luego administra esa libertad y actúa como su garante. Su tarea es ser productora de libertad, pero a la vez, impone «limitaciones, controles, coerciones, obligaciones con amenazas» ${ }^{37}$.

El sistema disciplinario configuraba una realidad artificial, las instituciones de encierro se perfilaban en función de un ideal de sociedad perfectamente disciplinada y obediente. Por nuestra parte, consideramos que, en el liberalismo, se configura artificialmente una idea de «naturalidad» de la sociedad civil. Esa naturalidad es tan artificial como las instituciones disciplinarias porque es el resultado de prácticas gubernamentales, es decir, de un ejercicio de poder político. Foucault muestra que los Estados deben producir una legislación internacional de intervención para evitar la hegemonía de un país sobre los demás (EE. UU., desde su independencia, impuso tarifas aduaneras proteccionista contra la hegemonía inglesa).

Asimismo, el mercado no es un elemento natural, hay políticas para crear compradores por medio de mecanismos de asistencia. Igualmente, debe haber

34 Foucault, M., Seguridad, territorio y población, p. 137.

35 Foucault, M., Nacimiento de la biopolítica, En sus manuscritos de la primera clase El filósofo asevera que es necesario: «Estudiar al liberalismo como marco general de la biopolítica», en la clase señala: «una vez que se sepa que es ese régimen gubernamental denominado liberalismo se podrá captar que es la biopolítica», p. 41.

36 Ibid., p. 83.

37 Ibid., p. 84. 
una legislación antimonopólica y, por último, Foucault marca que los obreros deben tener una calificación necesaria para la división social del trabajo, pero sobre todo deben carecer de herramientas políticas para actuar sobre el mercado laboral ${ }^{38}$.

Además, la línea divisoria entre el estado de libertad y un estado de peligrosidad es regulada por la seguridad gubernamental. Pero es propio del capitalismo extender los emprendimientos económicos a inversiones cada vez más peligrosas. La libertad capitalista conquista el espacio que antes ocupaba un estado de cosas peligrosas. Lo cierto es que en el siglo XIX hubo una fascinación por la peligrosidad: literatura policial, campañas de vacunación e higiene. El expansionismo imperialista del siglo XIX se explica como resultado de esta racionalidad liberal y el gobierno debe crear nuevos mecanismos de seguridad: cajas de ahorro, planes de seguridad laboral, seguridad médica, etc. Las estrategias de seguridad son el reverso y la condición del liberalismo ${ }^{39}$.

Con todo, el discurso en el que se expresa la racionalidad liberal no deja de estar ligado a una fobia por el Estado. Pero nuevamente el filósofo francés insiste en no interpretar este fenómeno como un crecimiento desmedido del Estado, sino más bien como el proceso inverso. Lo que caracteriza a las sociedades occidentales de mitad del siglo XX es la proyección de un Estado mínimo. Hay dos formas, desde una gubernamentalidad de Partido político, que signaría al último período del régimen soviético; y la gubernamentalidad liberal. Foucault rechaza el postulado según el cual, frente a un Estado represor, éste necesariamente debe ser calificado de fascista y enfrentado por mecanismos de terrorismo clandestino e insurgente. La propuesta del filósofo parece ir por la afirmación de los derechos de los gobernados, pero más adelante no profundiza esta idea.

Vázquez García acierta al considerar que las tecnologías del yo y las prácticas de libertad vienen a reemplazar las estrategias de gobierno. Sin embargo, no se comprende por qué insistir en que las técnicas del gobierno neoliberal nos ayudarían a entender ciertas prácticas de libertad. Si bien allí se enfatiza en la autonomía de los gobernados, en la cultura psicoterapéutica, en la autorresponsabilidad, en tomar a cada desocupado como un empresario de sí mismo que debe optimizar sus propios recursos ${ }^{40}$. En cambio, nuestra lectura nos lleva a enfatizar que Foucault, por un lado, rechaza la idea de libertad en el modelo liberal como simple ideología, pero por el otro, sólo puede ser entendida como un mecanismo de poder. En cuanto tal nunca deja de ser un sistema de dominación, y es por ello, que su proyecto debe abandonar las estrategias de gobierno y profundizar una comprensión ética de los sujetos. Nuestra opinión es que el Liberalismo no tiene ningún privilegio ético respecto de los demás modelos políticos. El

38 Ibid., p. 85.

39 Ibid., p. 86.

40 Vázouez García, F., o. c., p. 15. 
«ethos crítico ${ }^{41}$ respecto del Estado no es un rasgo diferenciador del Liberalismo, lo que Foucault toma de ella es cómo en su formación histórica está ligada a los mecanismos de regulación y cómo reaparece en la sociedad contemporánea.

Por último, resulta evidente que, con el advenimiento de la vigilancia disciplinar y fundamentalmente con las políticas de seguridad en el orden poblacional la figura del soberano ha sido modificado. Y esto se advierte en la diferencia entre los primeros textos contractualistas y sus últimas formaciones teóricas. La figura del soberano es alterada con mayor profundidad por la gubernamentalidad, que por la disciplina. Desde el pensamiento contractualista de Rousseau, reaparece la cuestión de la soberanía, pero a partir de ese momento, va a pasar a estar ligada a la voluntad general del pueblo.

Por último, podemos comprender que los aportes realizado por Antonio Negri y en especial por Gilles Deleuze están referidos a las mutaciones de las relaciones de poder en el nivel de lo micro. Lo que Deleuze denomina sociedad de control, tiene que ver con la crisis de las disciplinas. Los hospitales crean consultorios externos, la empresa reemplaza a la fábrica, hay una modulación de los sueldos y una competencia entre trabajadores de un mismo nivel. El control social pasa a realizarse sobre espacios abiertos ${ }^{42}$. Esta característica parece derivarse de los mecanismos de seguridad que funcionan al configurar una serie abierta de acontecimientos aleatorios.

\section{CONCLUSIONES}

Hemos podido ver que el corte histórico realizado por Foucault, a mitad del siglo XVIII es el momento cuando emergen dos nuevas formas de ejercicio del poder: lo disciplinario y la seguridad, ambos se configuran en oposición al poder soberano. Unos de los peligros de la hipótesis de una triangulación sistémica del poder político es borrar las discontinuidades marcadas por los estudios foucaultianos. Nuestra hipótesis ha sido que los mecanismos de seguridad se despliegan en los dos planos analíticos que hemos intentado examinar: tanto en lo micro como en lo macro.

El hecho más sobresaliente de nuestra investigación quizás sea el elemento a remarcar, según el cual, hay en lo micro una normalización propiamente de los mecanismos de seguridad y que se distinguen de la normación disciplinaria.

${ }^{41}$ Ibíd., p. 16 recordemos que el comunismo - por poner un simple ejemplo- tiene una posición igualmente crítica respecto de la función del Estado. A izquierda y a derecha, el Estado recibe fuertes cuestionamientos, el Liberalismo no intentan desarticular la estructura profunda del orden estatal.

Foucault, M., Defender la Sociedad, allí el filósofo afirma que los mecanismos de biopolítica y de los de soberanía funcionan de un mismo modo en Estados socialistas y en no socialistas., p. 237.

42 Deleuze, G., «Control y devenir» $\mathrm{y}$ «Post-scriptum sobre las sociedades de control». En: Deleuze, G., Conversaciones, Editora Nacional, Madrid, 1990. 
Normalización biopolítica y normación disciplinaria se hallan ambas al nivel micro, no son incompatibles. A su vez, ciertos ejercicios de la gubernamentalidad se establecen a nivel macro - por ejemplo, las regulaciones sobre la población-. Además, estos ejercicios regulatorios chocan y alteran el orden legal del poder soberano.

Hemos intentado demostrar: 1) las diferencias entre los mecanismos soberanos y disciplinarios, en razón al paso del suplicio al encierro; 2) las diferencias entre los mecanismos disciplinarios y los reguladores, respecto de la normalización; 3) las diferencias entre los mecanismos reguladores y los soberanos, en cuanto al control del territorio soberano y de la población por el gobierno.

Creemos que sería posible insistir en una serie de interrogantes al respecto: ¿qué compatibilidades persisten entre lo soberano y lo disciplinarios? ¿Qué compatibilidades entre lo disciplinario y la seguridad? ¿Qué compatibilidades hay entre lo soberano y lo regulatorio? ¿Se cumple en los cursos de Foucault del 78 y del 79 la explicación que relaciona los mecanismos de seguridad con la biopolitica y, a la vez, con la gubernamentalidad?

El nominalismo metodológico nos propone un método que posee grandes beneficios, para evitar cualquier razonamiento deductivo que antes no depende de comprobaciones empíricas en base a datos históricos concretos. Y debemos enfatizar que los estudios sobre elementos globales, sobre las relaciones entre los Estados-nación son igualmente estudiados por este mismo método, pero siempre con el imperativo de permanecer en datos concretos y no partir de los universales que fueron configurados por la filosofía política clásica: Estado, Naturaleza, libertad. Incluso la lucha de clases debe atender sus condiciones materiales concretas y no partir de un ideal metafísico.

Universidad Nacional de General Sarmiento (Argentina)

Darío Peralta

cuadrosfilosoficos.1@gmail.com

[Artículo aprobado para publicación en diciembre de 2016] $]^{43}$

43 Revisado en julio de 2020. 